\title{
Microwave-Assisted Synthesis of Chitosan/Polyvinyl Alcohol Silver Nanoparticles Gel for Wound Dressing Applications
}

\author{
Nguyen Thi Hiep, ${ }^{1}$ Huynh Chan Khon, ${ }^{1}$ Vo Van Thanh Niem, ${ }^{2}$ Vo Van Toi, \\ Tran Ngoc Quyen, ${ }^{3}$ Nguyen Dai Hai, ${ }^{3}$ and Mai Ngoc Tuan Anh $^{4}$ \\ ${ }^{1}$ Tissue Engineering and Regenerative Medicine Laboratory, Department of Biomedical Engineering, International University, \\ Vietnam National University, Ho Chi Minh City (VNU-HCMC), HCMC 700000, Vietnam \\ ${ }^{2}$ The Center for Molecular Biomedicine, University of Medicine and Pharmacy, HCMC 700000, Vietnam \\ ${ }^{3}$ Institute of Applied Materials Science, Vietnam Academy of Science and Technology, HCMC 700000, Vietnam \\ ${ }^{4}$ Research Laboratories of Saigon Hi-Tech Park, HCMC 700000, Vietnam
}

Correspondence should be addressed to Nguyen Thi Hiep; nthiep1981@gmail.com

Received 6 June 2016; Accepted 15 September 2016

Academic Editor: Karol Kyzioł

Copyright (C) 2016 Nguyen Thi Hiep et al. This is an open access article distributed under the Creative Commons Attribution License, which permits unrestricted use, distribution, and reproduction in any medium, provided the original work is properly cited.

\begin{abstract}
The purpose of this study was to fabricate chitosan/poly(vinyl alcohol)/Ag nanoparticles (CPA) gels with microwave-assistance for skin applications. Microwave irradiation was employed to reduce silver ions to silver nanoparticles and to crosslink chitosan (CS) with polyvinyl alcohol (PVA). The presence of silver nanoparticles in CPA gels matrix was examined using UV-Vis spectroscopy, transmission electron microscopy, and X-ray diffraction. The interaction of CS and PVA was analysed by Fourier transform infrared spectroscopy. The release of silver ions was determined by atomic absorption spectrometry. The antimicrobial properties of CPA gels against $P$. aeruginosa and $S$. aureus were investigated using agar diffusion method. Finally, the biocompatibility and woundhealing ability of the gels were studied using fibroblast cells (in vitro) and mice models (in vivo). In conclusion, the results showed that CPA gels were successfully fabricated using microwave irradiation method. These gels can be applied to heal an open wound thanks to their antibacterial activity and biocompatibility.
\end{abstract}

\section{Introduction}

Antimicrobial materials containing antibacterial agents have been widely investigated for possible uses in wound healing applications. Recently, they have been fabricated using different methods such as electrospinning [1], hydrogel system [2], and gas leaching [3] in order to incorporate antibacterial agents into the materials. They also have been prepared with various material combinations to increase their antibacterial property, eliminate toxicity [4], and shorten the wound healing process. A good combination of biopolymers can take advantage of its components. For example, Zhou et al. fabricated AgNPs loaded gelatin/carboxymethyl chitosan hydrogel. Results showed that this combination had increased mechanical strength, water absorption, and antibacterial activity compared to its components alone [5]. In another study, Zan et al. modified poly(L-lactic acid) (PLLA) film with AgNPs loaded PVA hydrogel using oxygen plasma treatment, UV-initiated graft polymerization, and chemical grafting methods. The modified film was reported to have effective antibacterial activity and biocompatibility [6].

Having been well known for its antibacterial property, chitosan (CS) has been one of the most common biomaterials used in tissue engineering. Its usefulness comes from favourable properties such as nontoxicity, biocompatible property, and biodegradable property $[7,8]$. However, when being used alone, CS is easy to lose its mechanical strength after absorbing wound exudate and reduce its degradation time. Therefore, CS is often cross-linked with other synthetic polymers such as poly(vinyl alcohol) [9] and polycaprolactone [10] to improve its mechanical strength. 
Beside CS, the use of silver nanoparticles in medical treatment has also increased owing to their high and longlasting antibacterial activities against a broad spectrum of bacteria [11, 12] and low toxicity to human cells [13-21]. The antibacterial activity of AgNPs, which offers an opportunity to make better antiseptic wound dressing, is associated with the release of $\mathrm{Ag}$ ions. Therefore, many studies have been performed to investigate the AgNPs loaded polymer matrices with the focus on controlling the release of AgNPs to prolong their antibacterial properties during healing process and on their usage as antibiotic substitutes [22, 23].

Although both CS and AgNPs have broad antimicrobial spectra to both Gram-negative and Gram-positive bacteria, their antibacterial mechanisms were different. In case of CS, the CS structure, which has positive charge, interacted with the negative charge of microbial cell membranes [24], the interaction between AgNPs and bacteria was based on the electrically generated $\mathrm{Ag}^{+}$ions. These properties suggest that CS can kill the bacteria if they enter CS matrix while AgNPs can diffuse and eliminate adjacent bacteria [25]. Therefore, combination of CS and AgNPs has been included in the research trends of many scientists [26-28].

Moreover, CS/AgNPs composites have been widely investigated and combined together with PVA to be applied for many different applications, especially for skin wound dressing [29]. Beside biodegradability, biocompatibility, hydrophilic property, and gelation ability [3], PVA could improve the wound exudate absorption of the hydrogel matrix so that CS and AgNPs can easily target and kill bacteria. Besides, the -OH groups of PVA could involve in the reduction of $\mathrm{Ag}^{+}$to $\mathrm{Ag}^{0}$ without using any reducing agents $[29,30]$. Many hybrid hydrogels combining PVA, CS or their mixture with AgNPs have been developed using various techniques in order to improve their antimicrobial activity and enhance the wound-healing process [9, 28, 31]. However, to the best of our literature research, the use of microwave irradiation for both AgNPs forming and CS crosslinking with PVA without using reducer has not been performed elsewhere.

The objective of this study was to fabricate CS/PVAAgNPs hydrogels using microwave-assisted method. The effects of AgNPs concentration on the antimicrobial property of hydrogels were investigated. Microwave irradiated CS/ PVA-AgNPs hydrogels with various AgNPs concentrations were characterized using UV-Vis spectroscopy, transmission electron microscopy (TEM), X-ray diffraction (XRD), Fourier transform infrared (FT-IR) spectroscopy, and atomic absorption spectrometry (AAS). Their antibacterial property was assessed using agar diffusion method. Their biocompatibilities were evaluated using fibroblast cells and mice models.

\section{Materials and Methods}

2.1. Materials. Poly(vinyl alcohol) (PVA, hydrolysis degree of 99.0-99.8\%), chitosan (CS, from shrimp shells, $\geq 75 \%$ deacetylated), and silver nitrate $\left(\mathrm{AgNO}_{3}, 99.998 \%\right)$ were purchased from Sigma Aldrich, USA. Mueller-Hinton agar was purchased from Becton Dickinson, USA. Fibroblast cell line (L-929) was purchased from ATCC. P. aeruginosa (ATCC
27853) and S. aureus (ATCC 25923) were used for antibacterial assays. Swiss-albino mice (age of 4 weeks, 16-20 g) were provided by Pasteur Institute of Ho Chi Minh City, Vietnam.

2.2. Fabrication of CS/PVA-AgNPs Hydrogels. To fabricate CS/PVA-AgNPs hydrogels, CS/PVA solution, labelled as CP, was prepared first by mixing chitosan $2 \% \mathrm{w} / \mathrm{v}$ (prepared in acetic acid $2 \% \mathrm{w} / \mathrm{v}$ solution) with PVA $10 \% \mathrm{w} / \mathrm{v}$ solutions (prepared in warm water) with volume ratio of $1: 1$. Then, silver nitrate solution, which was prepared by dissolving silver nitrate powder in water to get $10 \% \mathrm{w} / \mathrm{v} \mathrm{AgNO}_{3}$, was added into the prepared CP solution and mixed well to get the final concentration of $\mathrm{AgNO}_{3}$ 0.5\% w/v and $1 \% \mathrm{w} / \mathrm{v}$ in CP solution, respectively named as $\mathrm{CPA}_{0.5}$ and $\mathrm{CPA}_{1}$. Each solution was poured into a separate beaker and irradiated in microwave oven (Hitachi, Japan) at $800 \mathrm{~W}$ for 90 seconds to form gels. The gels were lyophilized using a freeze dryer (Ilshin Lab. Co., Ltd, USA) for characterization. All samples were sterilized under UV irradiation for in vitro and in vivo studies.

2.3. Characterization of CS/PVA-AgNPs Hydrogels. After the hydrogels were synthesized, the presence of AgNPs in the hydrogels was examined by UV-Vis spectra analysis with the wavelength from 200 to $800 \mathrm{~nm}$ using a UV-Vis spectrometer (Thermo Scientific Genesis 10S, US). The morphology of AgNPs in gel matrices was observed using transmission electron microscope (JEOL JEM1400, Japan). The crystalline phase of AgNPs in lyophilized hydrogel was obtained using $\mathrm{X}$-ray diffraction (Bruker X-ray diffractometer) with $\mathrm{Cu} \mathrm{Ka}$ radiation $(\lambda=1.54060 \AA)$ and the step size was $0.02^{\circ} \mathrm{s}^{-1}$. The interactions between PVA and chitosan were examined by analysing FT-IR spectra collected from a FT-IR analyser instrument (PerkinElmer Spectrum GX, USA) within the wave number region of 4000 to $500 \mathrm{~cm}^{-1}$.

\subsection{In Vitro Study}

Release of Silver Ions. In order to check the release rate of Ag ions, a calibration curve was made by measuring various silver solutions with a defined silver ion concentration using atomic absorption spectrometry (AAS, SpectrAA 220FS, Varian, USA), and then the release rates were determined by measuring silver solution at different time-course release. Briefly, a calibration curve was made firstly by dissolving completely one sample (circle, $1 \mathrm{~cm}$ in diameter) $5 \mathrm{~mL}$ in nitric acid, and the obtained solution was used as stock solution. Then, the stock and series of the diluted solution were measured by AAS to create a calibration curve. After that, 21 other samples were immersed in 21 tubes, and each tube contains $5 \mathrm{~mL}$ F12 medium. Then, the tubes were incubated in incubator at $37^{\circ} \mathrm{C}$. Three tubes were taken out at different time points (i.e., 1, 6, 12, 24, 48, 168, and 336 hours), and the release of silver ions from the membranes in the F12 medium was determined by AAS [32].

The antibacterial activity of the hydrogels was assessed against $P$. aeruginosa and $S$. aureus strains using agar diffusion method. Briefly, the bacteria in sterilized medium were inoculated using microbial culture and kept in the rotary shaker at $150 \mathrm{rpm}, 37^{\circ} \mathrm{C}$ for 16 hours. Then, bacteria were 
centrifuged, washed, and suspended in $2 \%$ phosphate buffer. The final bacteria concentration was adjusted to $1-2 \times$ $10^{9} \mathrm{CFU} / \mathrm{mL}$ using UV spectrophotometer. Antimicrobial activity of the membranes was determined by qualitative evaluation according to AATCC 147, in which freeze-dried samples $\mathrm{CP}, \mathrm{CPA}_{0.5}$, and $\mathrm{CPA}_{1}$ with diameter of $1 \mathrm{~cm}$ were placed on the lawn of bacteria in an Mueller Hinton agar plate [14]. The plates were incubated at $37^{\circ} \mathrm{C}$ for 24 hours before visualizing assessment and measuring the inhibition zone. Bactericidal activity of membranes was evaluated by comparison of their inhibition zone.

For cytotoxicity test, the cellular viability of mouse fibroblast cells (L-929) on series of the dilution (100\%, 50\%, 25\%, $12.5 \%$, and $0 \%$ ) of the extracted solution was determined using the MTT assay. For the preparation of the extracted solution, $5 \mathrm{mg}$ gel was incubated in $5 \mathrm{~mL}$ RPMI media with $10 \%(\mathrm{v} / \mathrm{v})$ fetal bovine serum (FBS) and $1 \%$ penicillin/streptomycin antibiotics for 3 days at $37^{\circ} \mathrm{C}$, under shaking condition at $100 \mathrm{rpm}$ in an incubator, and the extracted solution was obtained by filtration membrane. The L-929 cells were seeded in 96-well culture plate with the concentration of 1 $\times 10^{4}$ cells $/ 100 \mu \mathrm{L}$ and incubated for 24 hours at $37^{\circ} \mathrm{C}, 5 \%$ $\mathrm{CO}_{2}$. Diluted extract solutions were added to the cell-seeded tissue culture plates, and cell-seeded wells with media only ( $0 \%$ extract solution) were also prepared as a control. The plates were incubated for another 3 days at $37^{\circ} \mathrm{C}$ and $5 \% \mathrm{CO}_{2}$. Then, MTT solution was added to the wells and incubated for 4 hours. Media were discarded from the wells and replaced with $200 \mu \mathrm{L}$ of DMSO to dissolve the formazan salts. Cell viability was relatively quantified by measuring the absorbance at $590 \mathrm{~nm}$ using an ELISA reader (Turner Biosystems CE, Promega Corporation, USA). These experiments were replicated four times and cell viability was calculated as percentage relative to the control. The photos of cell proliferation on plate were also captured.

2.5. In Vivo Study. The wound healing rates of $\mathrm{CPA}_{0.5}$ and $\mathrm{CPA}_{1}$ gels were studied by spreading gels on the dorsal opened-wounds of mice. Firstly, mice were anesthetized by dimethyl ether and fixed on table with hair being shaved at their backs. Next, povidone solution was used to clean up the implant site. Two full thickness wounds with diameter of $1 \mathrm{~cm}$ were created on each mouse's dorsal, and $0.1 \mathrm{~mL}$ of gel was dressed on. The nontreated mice were used as the control. To monitor the healing process of skin wound, the pictures of wounds were captured after a duration of 15 days.

At day 15 after implantation, mice were sacrificed. The samples were extracted together with the adjacent skin area and fixed in $10 \% \mathrm{v} / \mathrm{v}$ formaldehyde solution. The samples were dehydrated, embedded in paraffin, and sectioned to get $5 \mu \mathrm{m}$ thickness slice using a microtome (Thermo Scientific HM 325, US). The slices were stained with Hematoxylin and Eosin (H\&E) for histological analysis under light microscopy.

\section{Results}

3.1. Characterization of CS/PVA-AgNPs Hydrogels. The purpose of this study was to prepare a chitosan/polyvinyl alcohol/AgNPs gels matrix without using any reducer. Therefore,

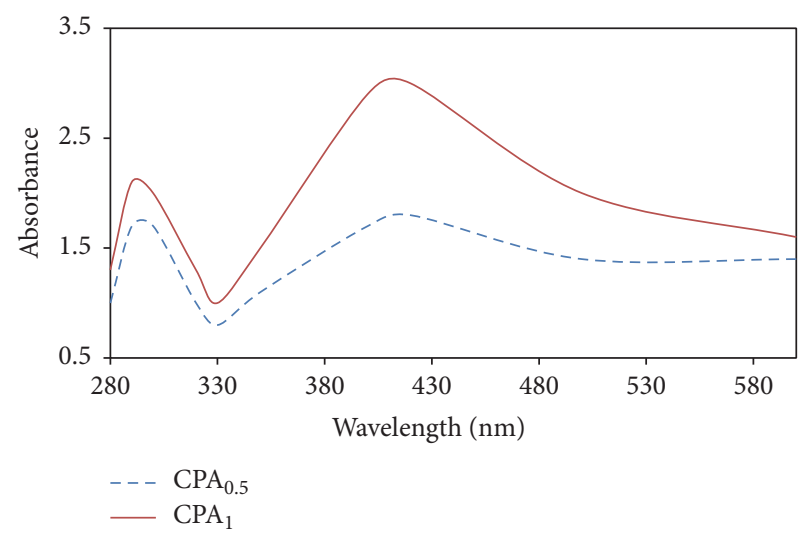

Figure 1: UV-Vis absorption spectra of $\mathrm{CPA}_{0.5}$ and $\mathrm{CPA}_{1}$.

microwave irradiation, which could crosslink polymer [33], was employed in this investigation. The success of AgNPs formation was visually confirmed by the colour of the gels and the UV-Vis spectra. After microwave irradiation, the colour of hydrogels changed from white to deep brown, which indicated the presence of silver in the nanoparticle form [29]. Besides, in the UV-Vis spectra (Figure 1), the spectrum of $\mathrm{CPA}_{0.5}$ and $\mathrm{CPA}_{1}$ hydrogel showed an absorption peak at $428 \mathrm{~nm}$, which was due to the localized surface plasmon resonance of AgNPs [30]. As presented in Figure 1, a broad absorption peak of AgNPs at low $\mathrm{AgNO}_{3}$ concentration in $\mathrm{CPA}_{0.5}$ hydrogel was obtained, while $\mathrm{CPA}_{1}$ showed that higher concentration of $\mathrm{AgNO}_{3}$ resulted in stronger sharp absorption. UV-Vis results indicated that the AgNPs distributed in $\mathrm{CPA}_{1}$ gel was higher than that in $\mathrm{CPA}_{0.5}$ gel.

The AgNPs morphology and distribution in $\mathrm{CPA}_{0.5}$ and $\mathrm{CPA}_{1}$ gels were also studied using TEM observation. AgNPs exhibited a spherical shape in both samples (presented in Figure 2). The sizes of AgNPs were measured based on TEM data. Results showed that the sizes of $\mathrm{PCA}_{0.5}$ ranged from 4 to $19 \mathrm{~nm}$ (Figures 2(a) and 2(b)), while the sizes of PCA1 were ranging from 3 to $16 \mathrm{~nm}$ (Figures 2(c) and 2(d)). Results showed that the amount of AgNPs in $\mathrm{PCA}_{1}$ was higher than that of $\mathrm{PCA}_{0.5}$ gel.

XRD profiles of $\mathrm{CP}$ and $\mathrm{CPA}_{0.5}$ gels were acquired to identify the crystalline structure of gels (Figure 3 ). Typically, the XRD pattern of the $\mathrm{CPA}_{0.5}$ had diffraction peaks at approximately $38.2^{\circ}$ and $44.2^{\circ}$, corresponding to the crystalline structure (111) and planes (200), respectively, of the standard Ag cubic phases $[34,35]$. The peak at approximately $20.9^{\circ}$ indicated the crystalline structure of CP [36]. The peaks at approximately $18^{\circ}, 27^{\circ}, 28^{\circ}$, and $31^{\circ}$ indicated the diffraction peaks of $\mathrm{CPA}_{0.5}$ after irradiation.

To examine the chemical interaction between PVA, CS and $\mathrm{Ag}$, the FT-IR spectra of $\mathrm{CP}, \mathrm{CPA}_{0.5}$ and $\mathrm{CPA}_{1}$ were depicted (Figure 4). The spectrum of CP shows peaks around 893 and $1160 \mathrm{~cm}^{-1}$ corresponding to saccharide structure. Beside several peaks clustering in the amide II peak ranging from 1250 to $1450 \mathrm{~cm}^{-1}$, there were strong absorption peaks at 1635 and $1541 \mathrm{~cm}^{-1}$, respectively, corresponding to amide I and amide III [37]. There was a significant reduction of 

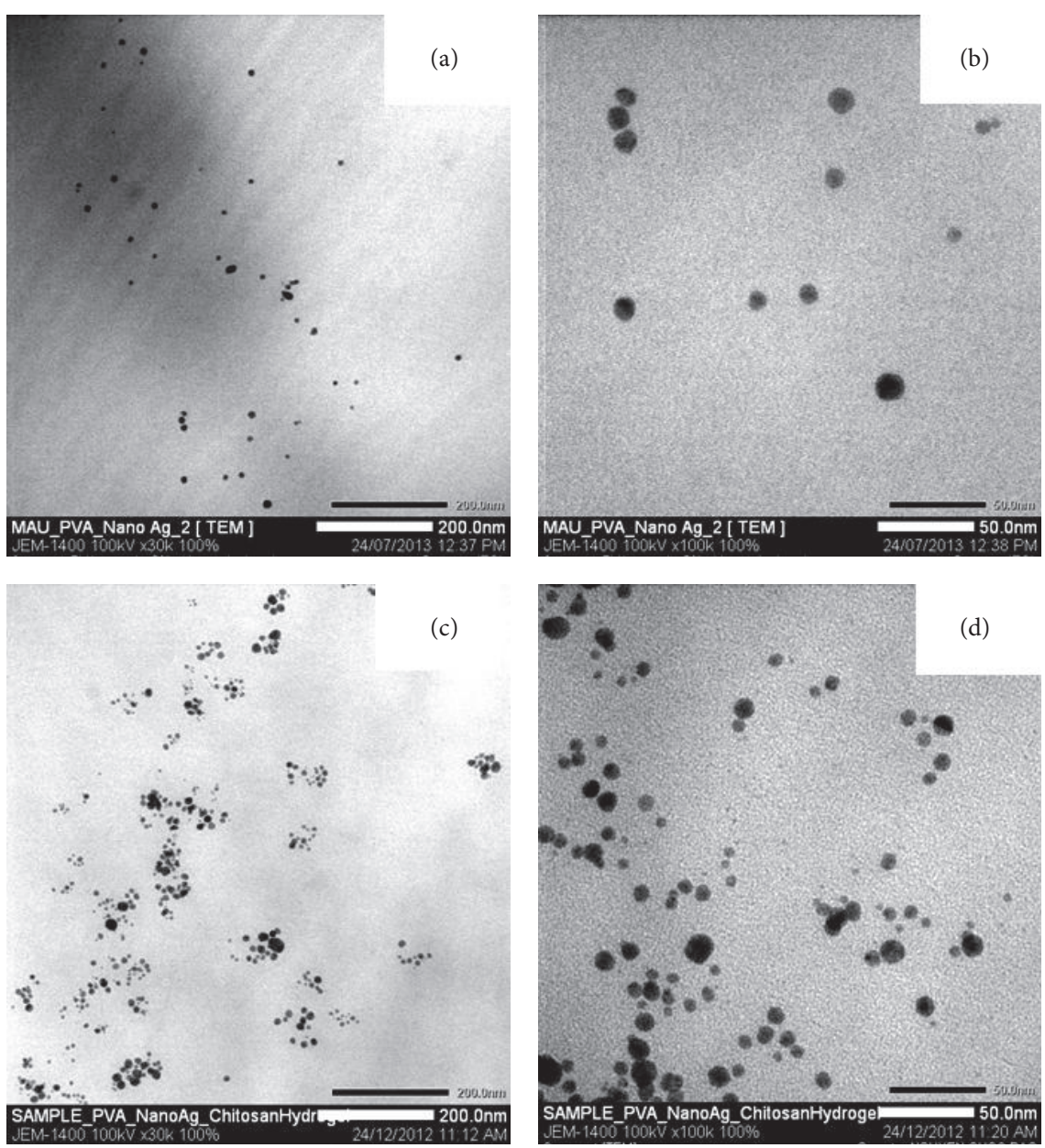

Figure 2: TEM images of $\mathrm{CPA}_{0.5}$ (a and b) and $\mathrm{CPA}_{1}$ (c and d) at $30 \mathrm{k}$ and $100 \mathrm{k}$ magnification, respectively.

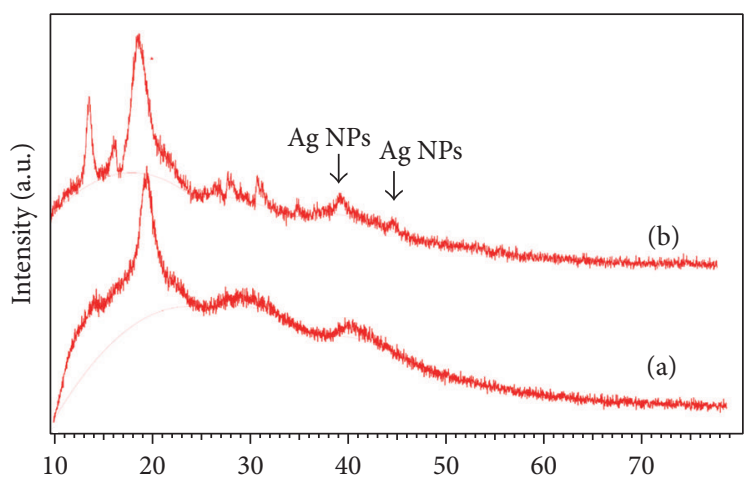

FIgURE 3: XRD profiles of CP (a) and $\mathrm{CPA}_{1}$ (b) gels.

intensity of the bands in amine region $\left(1250\right.$ to $\left.1635 \mathrm{~cm}^{-1}\right)$, as the contents were decreased from $100 \%$ for CP mixing to around $40 \%$ for $\mathrm{CPA}_{0.5}$ hydrogel and around $30 \%$ for $\mathrm{CPA}_{1}$ hydrogel. The decrease in the ratio of the absorbance at $1420 \mathrm{~cm}^{-1}$ relative to the presence of Ag NPs indicated the decoupling between the corresponding vibrations and the interactions between AgNPs and the - $\mathrm{OH}$ groups of the PVA chains. Besides, PVA and CS were expected to be dehydrated and to form the intermolecular ether bridge, which was indicated by the increase of the absorbance at $1250 \mathrm{~cm}^{-1}$ [30] after microwave irradiation. Herein, it could be concluded that microwave irradiation reduced $\mathrm{Ag}^{+}$to $\mathrm{Ag}^{0}$ as well as crosslinked PVA and CS to form CPA hydrogel.

3.2. In Vitro Study. Figure 5 shows the release rate of silver from $\mathrm{CPA}_{0.5}$ and $\mathrm{CPA}_{1}$ gels in $\mathrm{F} 12$ medium with respect to time as measured by AAS. In case of $\mathrm{CPA}_{0.5}$ gel the amount of silver ions released is $5.9 \mu \mathrm{g} / \mathrm{mL}$ within the first hour and increased fast to $12.8 \mu \mathrm{g} / \mathrm{mL}$ for the next 5 hours. From the sixth hour to the twelfth hour, the release rate increased from $12.8 \mu \mathrm{g} / \mathrm{mL}$ to $16.3 \mu \mathrm{g} / \mathrm{mL}$. Then, the release rate increased slightly after the first 12 hours and had the value of $18.9 \mu \mathrm{g} / \mathrm{mL}$ at 336 hours thereafter. In case of $\mathrm{CPA}_{1}$ gel, the amount of silver release was twice in comparison with the data of $\mathrm{CPA}_{0.5}$ gel. Briefly, the release rates of silver ions were 13.5, 25.4, 32.3, $33.2,34.2,35.5$, and 38.4 for $1,6,12,24,48,168$, and 338 hours, respectively.

In order to test the antimicrobial activity of samples, agar diffusion method was employed. Figure 6 shows that $\mathrm{CPA}_{0.5}$ and $\mathrm{CPA}_{1}$ had similar antibacterial activity against 

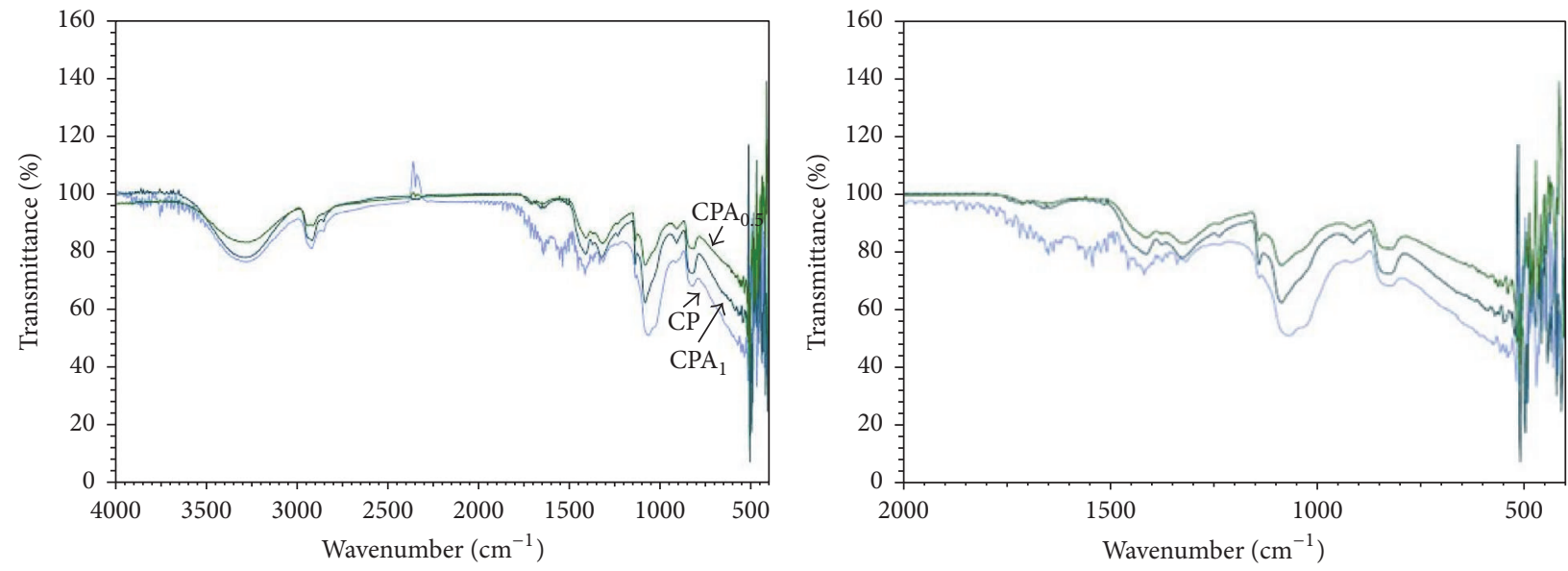

FIGURE 4: FT-IR spectra of CP, $\mathrm{CPA}_{0.5}$, and $\mathrm{CPA}_{1}$ gels.

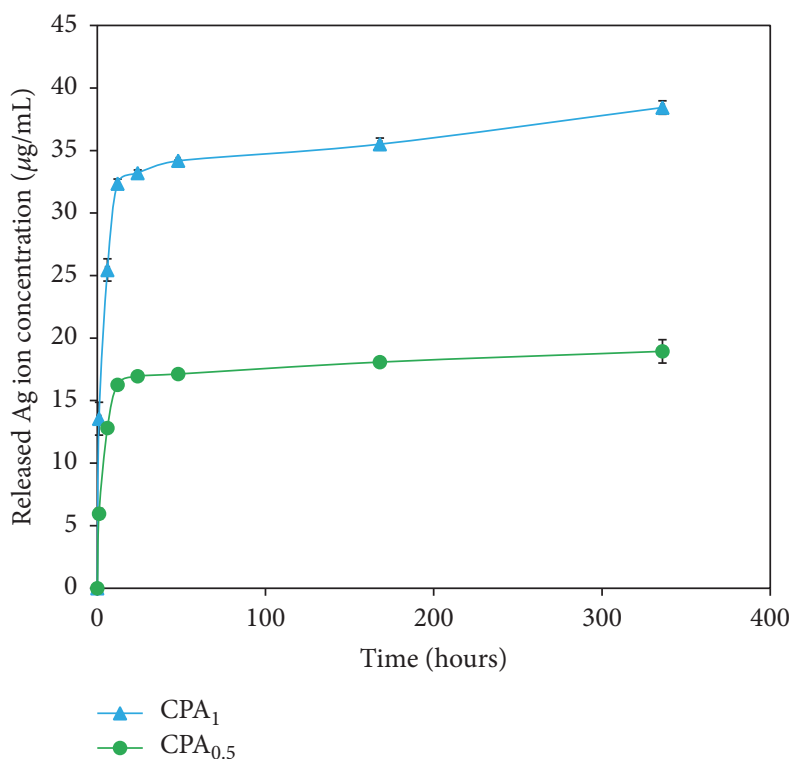

Figure 5: Silver release study from $\mathrm{CPA}_{0.5}$ and $\mathrm{CPA}_{1}$ gels in F12 medium.

P. aeruginosa as their inhibition zone was about $0.29 \mathrm{~cm}$ outward from the sample. For $S$. aureus, the inhibition zones of $\mathrm{CPA}_{1}$ and $\mathrm{CPA}_{0.5}$ gels were $0.23 \mathrm{~cm}$ and $0.29 \mathrm{~cm}$, respectively. Thus, results revealed that as the amount of AgNPs increased, the inhibition zone enlarged. In contrast, the inhibition zone was not observed in CP sample for both Gramnegative bacteria ( $P$. aeruginosa) and Gram-positive bacteria (S. aureus).

Figure 7 shows the diagram of the percentage of cell viability of L-929 cells tested with the extracted solutions of $\mathrm{CP}, \mathrm{CPA}_{0.5}$, and $\mathrm{CPA}_{1}$. Results showed that the increase of Ag-NPs amount in hydrogels resulted in the decrease of the cell viability of hydrogels. Specifically, at the same concentration of $100 \%$ extracted solution, CP had $92 \%$ cell viability while $\mathrm{CPA}_{0.5}$ and $\mathrm{CPA}_{1}$ had approximately $80 \%$ and $76 \%$ cell viability. However, cell viability of all samples was still higher than $70 \%$, which was the threshold between cytotoxicity and noncytotoxicity, so they can be considered noncytotoxic. Besides, the captured images of fibroblast cells which proliferated on $100 \%$ extracted solution of gels showed that the amount of fibroblast cells proliferated on the extracted solution of $\mathrm{CP}$ is greater than that of $\mathrm{CPA}_{0.5}$ and $\mathrm{CPA}_{1}$. However, the amount of fibroblast cells on CP gels is less than that of tissue culture plate (TCP). In comparison of $\mathrm{CPA}_{0.5}$ and $\mathrm{CPA}_{1}$, the amount of cells is visually equal.

3.3. In Vivo Study. The morphology of wounds from postsurgery to the day 15 after implantation is shown in Figure 9. The series of photos illustrated the three different phases of wound healing process, inflammation, proliferation, and remodelling. From day 0 to day 7, in which the inflammation and proliferation phases took place, results showed that the healing rate was similar on the control, $\mathrm{CPA}_{0.5}$, and $\mathrm{CPA}_{1}$ samples, indicated by the formation of a thick scab on the wound site, yet it was thinner in the case of CP hydrogel. On day 11, the thick scabs were removed and the wound size of all samples decreased appropriately $80 \%$ compared to the initial size. Besides, wound that was treated by CPA1 displayed no scab. At day 15, when the wound healing moved to the remodelling phase and no more scab remained on the wounds, the postimplantations were extracted and their histological structures were observed and are shown in Figure 10. According to the histological examination, newly synthesized fibrous tissue and sparse inflammatory cells in the dermis and subcutis were formed in both the control and CP samples. However, the treated wounds were covered with newly formed fibrous tissues and completely reepithelialized epidermis. In comparison with $\mathrm{CPA}_{0.5}$, histological staining images of $\mathrm{CPA}_{1}$ showed that this gel could decrease the inflammation of skin and induce skin-healing process better than $\mathrm{CPA}_{0.5}$ does.

\section{Discussion}

For skin healing process, a wound dressing is necessary to prevent infection. An ideal wound dressing must contain 

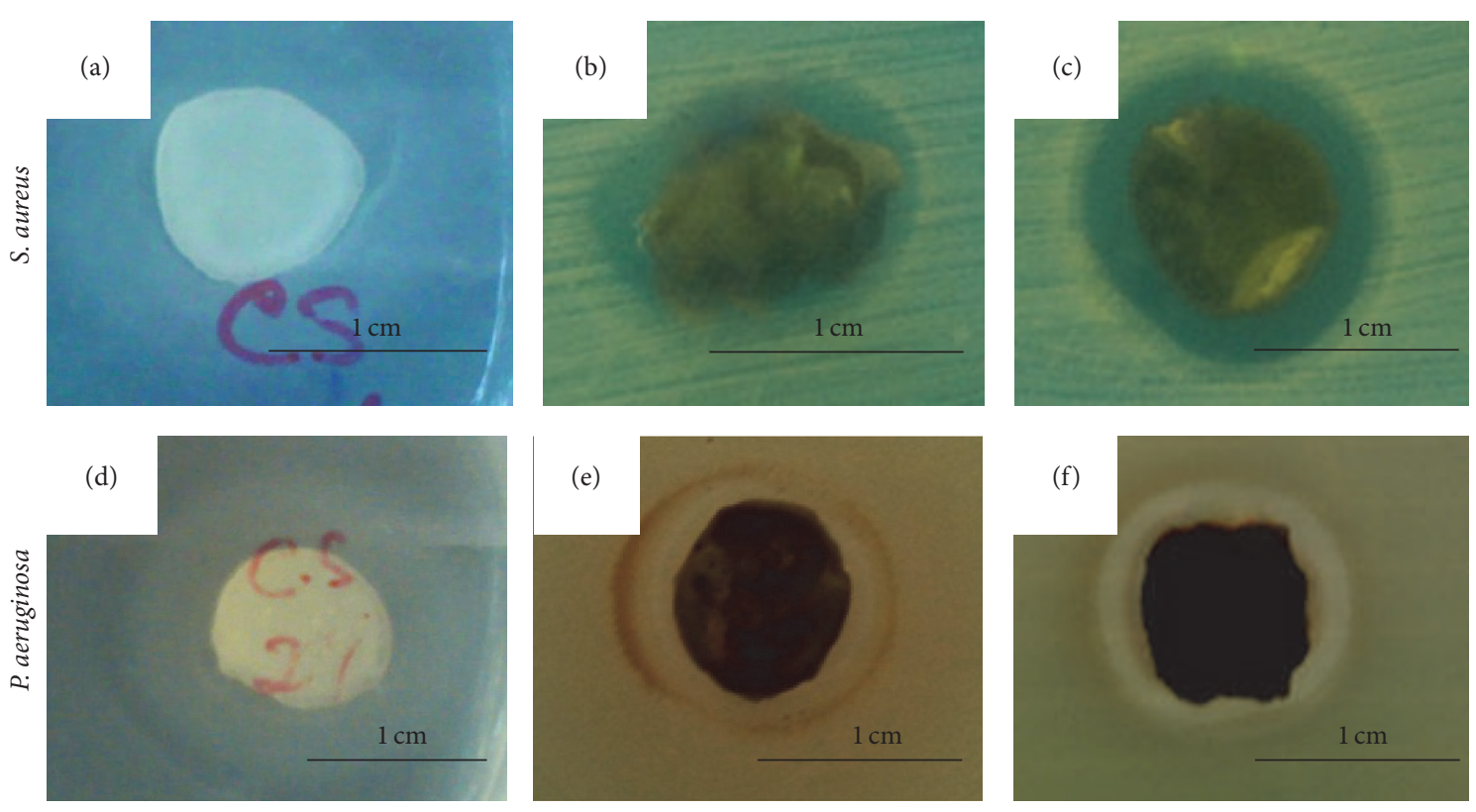

FIgURE 6: Antimicrobial activity against $S$. aureus (a-c) and P. aeruginosa (d-f) of CP (a and d), $\mathrm{CPA}_{0.5}\left(\mathrm{~b}\right.$ and e), and $\mathrm{CPA}_{1}(\mathrm{c}$ and f).

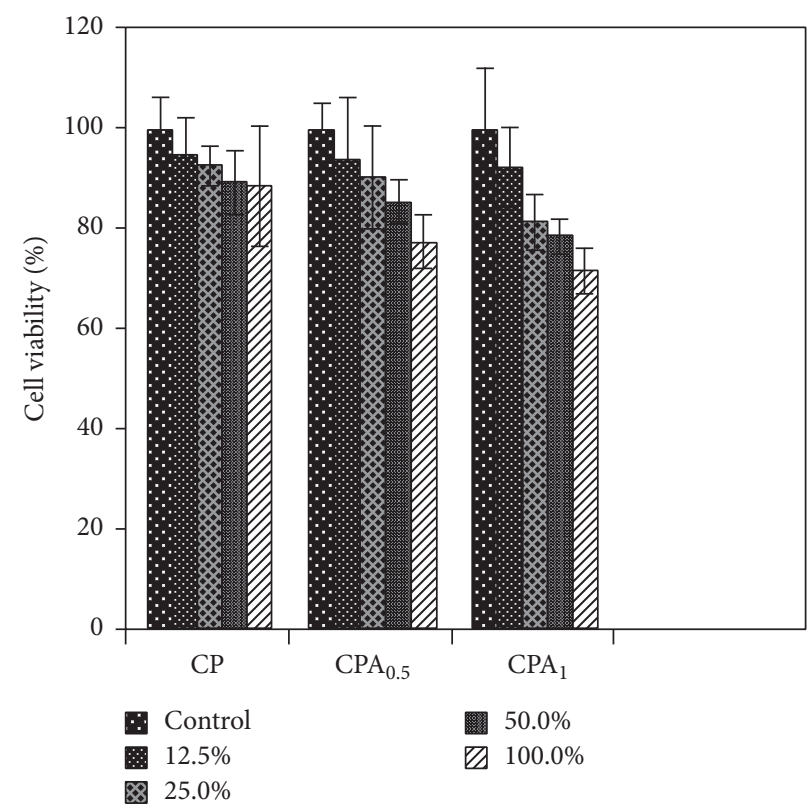

Figure 7: Toxicity of CP, $\mathrm{CPA}_{0.5}$, and $\mathrm{CPA}_{1}$ using MTT assay.

an antibacterial agent. An antimicrobial material containing AgNPs could be prepared by immobilizing or entrapping AgNPs in biopolymer matrix. This matrix is not only to control the release of $\mathrm{Ag}$ ions but also to increase and prolong the antibacterial activity of AgNPs. Besides antibacterial property, biopolymer matrices must possess other requirements such as biocompatibility, biodegradation, mechanical strength, and water absorption. Therefore, combinations of natural and synthetic polymers have been investigated for decades to take advantages of both sources. Among them, the combination of CS and PVA has been developed to act as both a reducer and a template for the immobilization of
AgNPs. There are several methods that can be applied to load AgNPs into CS/PVA matrix. For example, Li et al. developed a PVA/COS/AgNPs electrospun membrane that showed excellent antibacterial properties and biocompatibility [34]. Agnihotri et al. fabricated PVA/CS loading AgNPs by two separated steps, the crosslinking of PVA and CS followed by the immobilization of AgNPs [9]. Abdelgawad et al. electrospun the multicomponent (chitosan/silver-NPs/polyvinyl alcohol) for wound dressing applications. However, microwave irradiation has not been investigated so far.

In this study, microwave irradiation was employed to crosslink PVA with CS and reduce $\mathrm{Ag}^{+}$to $\mathrm{Ag}^{0}$. A uniform 

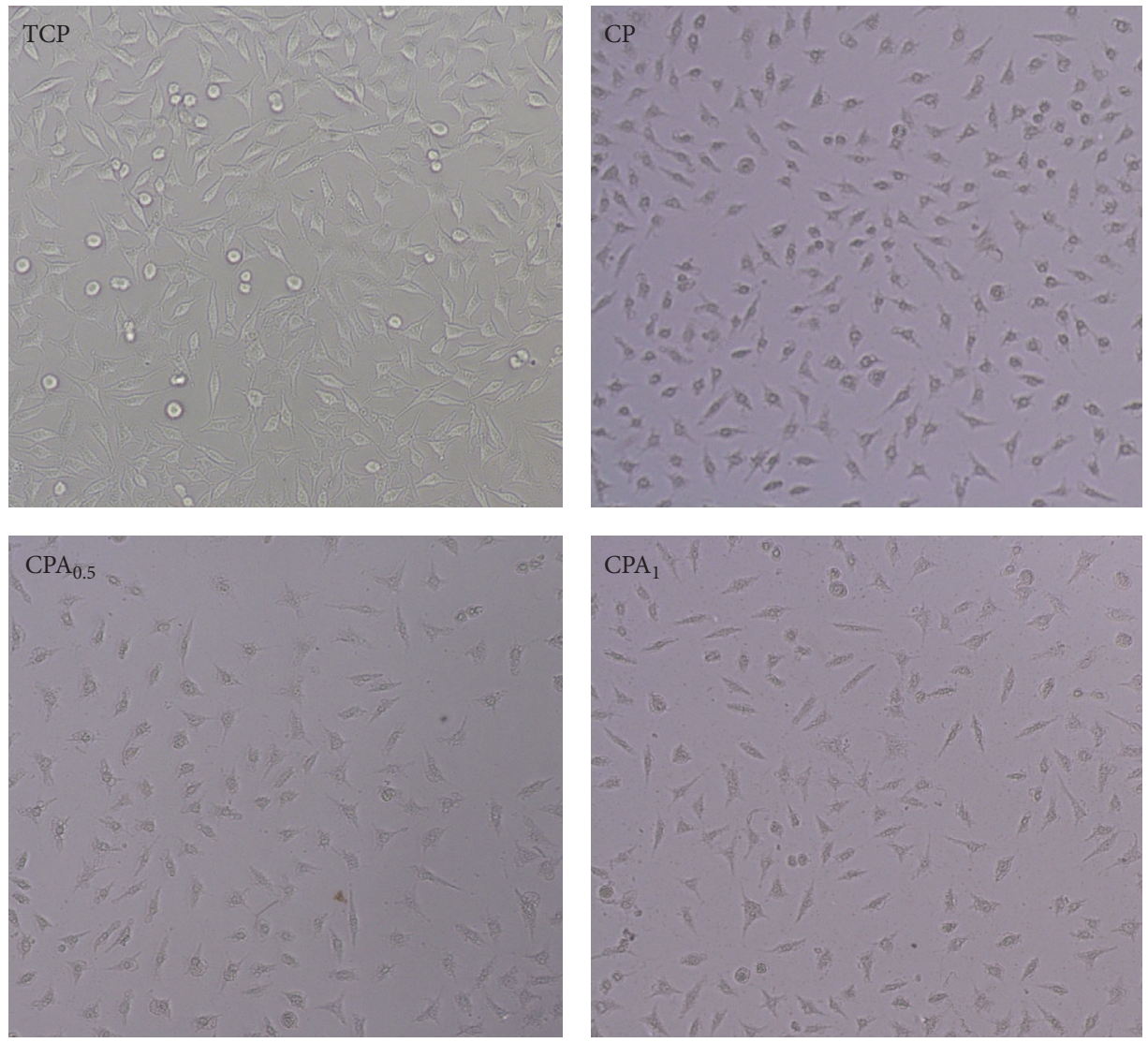

FIGURE 8: Cell proliferation on control (TCP) and the extracted solution of $\mathrm{CP}, \mathrm{CPA}_{0.5}$, and $\mathrm{CPA}_{1}$.

distribution of AgNPs inside the hydrogel matrix could be achieved thanks to the complex formation and noncovalent interactions between $\mathrm{Ag}$ ions and the functional groups in hydrogel network such as $-\mathrm{OH},-\mathrm{NH}_{2}$, and $-\mathrm{C}=\mathrm{O}$ [38-40]. $-\mathrm{OH}$ functional groups of PVA and CS could act as reducer that caused the reduction of ion $\mathrm{Ag}^{+}$to particle $\mathrm{Ag}^{0}$ [27]. Besides, microwave irradiation supported in the crosslinking process of polymer whose chains contain -OH groups such as chitosan and polyvinyl alcohol $[13,41]$. The advantage of this method is that CPA gels are fabricated without using any reducer; therefore, there is no need of further step to remove residual crosslinker and reducer. To confirm the success of AgNPs formation in CP hydrogel, UV-Vis spectrum, TEM observation, XRD, FT-IR spectrum analyses, and the release of $\mathrm{Ag}$ ions were performed. Results showed that CPA gels were fabricated successfully by using microwave-assistance, which was indicated by absorption peak at $428 \mathrm{~nm}$ in UVVis spectrum (Figure 1). Moreover, the decrease in the ratio of $1420 \mathrm{~cm}^{-1}$ in FT-IR spectrum (Figure 4) confirmed AgNPs formation in CP matrix. Besides, the presence of AgNPs was also confirmed by TEM observation. Results showed that the size of AgNPs distributed from 4 to $19 \mathrm{~nm}$ (Figure 2). Additionally, the crystal structure (111) and planes (200) in XRD profiles (Figure 3) indicated the presence of AgNPs. For medical applications, the biocompatibility of CPA gels is another important factor that needs to be confirmed. Beer et al. revealed that the amount of silver released determines cell viability of hydrogel. The results from Beer's study also indicated that cell viability was higher than $80 \%$ in samples which contained the percentage of silver lower than $2 \%$ [42]. Therefore, the percentage of silver amount was fixed under $2 \%$ in total amount and the release of $\mathrm{Ag}$ ions was performed and is shown in Figure 5. Results showed that the release rates of $\mathrm{Ag}$ ions from $\mathrm{CPA}_{0.5}$ and $\mathrm{CPA}_{1}$ were about $15 \mu \mathrm{g} / \mathrm{mL}$ and $32 \mu \mathrm{g} / \mathrm{mL}$, respectively, for nearly 24 hours. No significant change was observed after 24 hours. Besides, the antibacterial properties and biocompatibility of gels were assessed in this study. Figure 6 showed that the CP sample did not create inhibition zone in both Gram-positive and Gram-negative bacteria. $\mathrm{CPA}_{0.5}$ and $\mathrm{CPA}_{1}$ gels showed a similar antibacterial property against $P$. aeruginosa, while the increase in antibacterial activity against $S$. aureus was observed as the concentration of AgNPs increased (Figure 6), suggesting sample $\mathrm{CPA}_{1}$ had the antibacterial activity against $S$. aureus better than $\mathrm{CPA}_{0.5}$. Figures 7 and 8 show that both $\mathrm{CPA}_{0.5}$ and $\mathrm{CPA}_{1}$ did not generate toxicity in cell culture tests. Moreover, in in vivo tests, it was observed that both $\mathrm{CPA}_{0.5}$ and $\mathrm{CPA}_{1}$ could decrease the inflammation of skin and support new fibrous tissue and completely reepithelialized epidermis (Figure 10).

\section{Conclusion}

In this study, the antimicrobial CPA gels were formed under microwave-irradiated assistance. Results showed that 

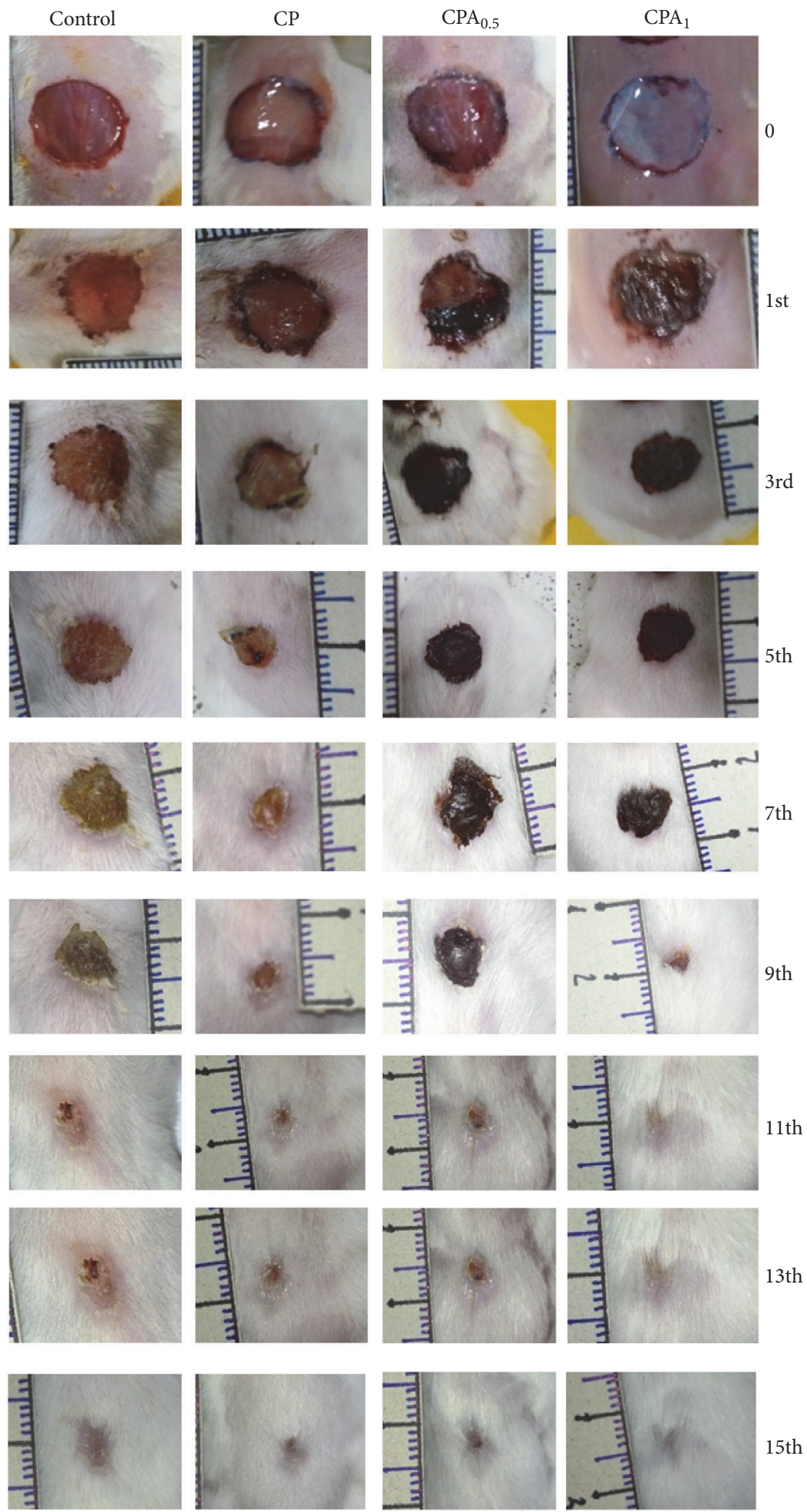

Figure 9: Photos of wounds treated with $\mathrm{CP}, \mathrm{CPA}_{0.5}$, and $\mathrm{CPA}_{1}$.

microwave did not only cross-link chitosan and polyvinyl alcohol but also reduced $\mathrm{Ag}^{+}$to $\mathrm{Ag}^{0}$. The CPA gels were successfully fabricated and characterized by UV-Vis spectra, TEM observation, FT-IR spectra, and XRD profiles. The release rate of silver ions increased if the concentration of
AgNPs increased. The antimicrobial tests indicated that $\mathrm{CPA}_{0.5}$ and $\mathrm{CPA}_{1}$ could act against both $P$. aeruginosa and $S$. aureus. However, the antibacterial activity against $S$. aureus was affected by the concentration of the released Ag ions. In vitro and in vivo study suggested that both $\mathrm{CPA}_{0.5}$ and $\mathrm{CPA}_{1}$ 

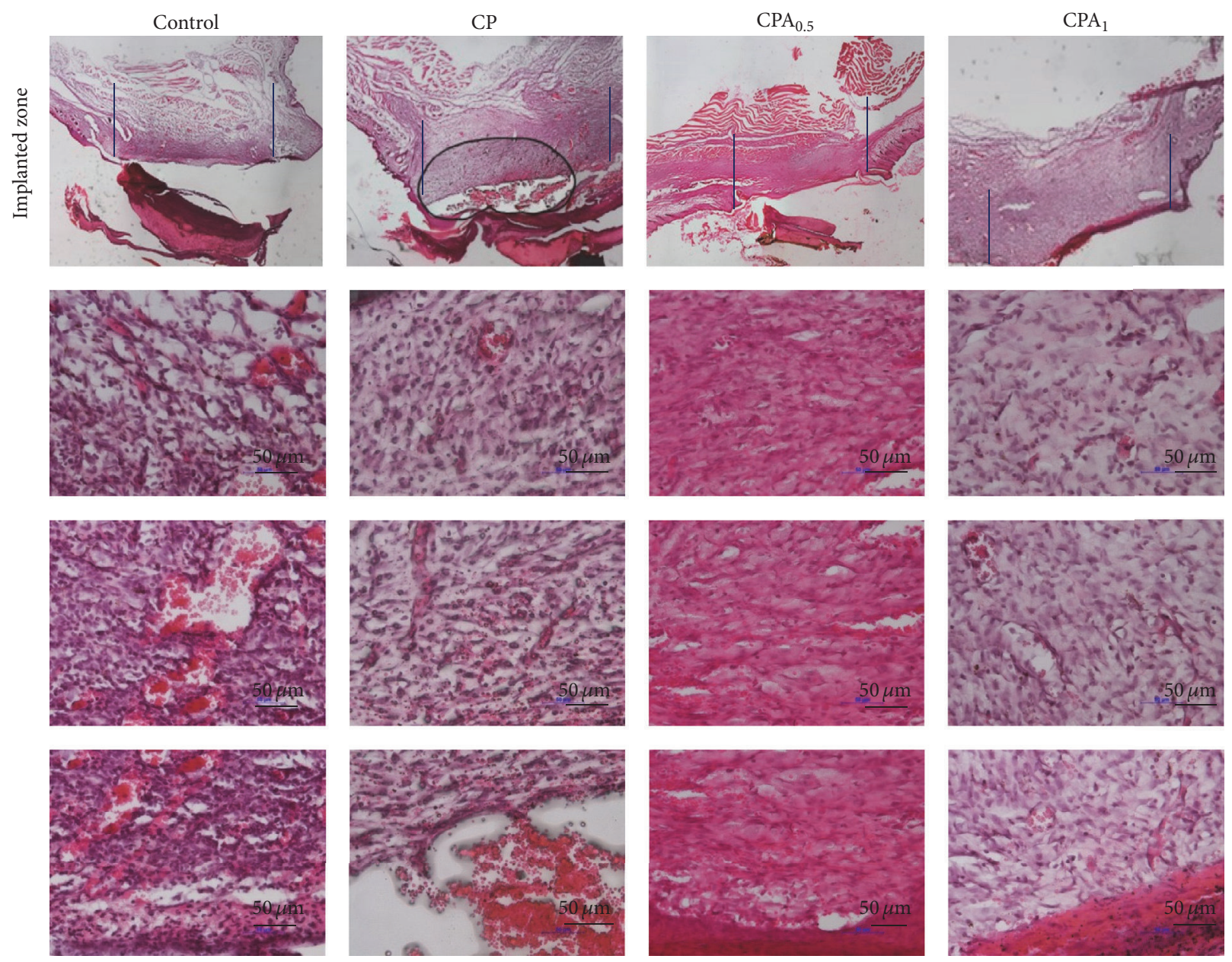

FIGURE 10: H\&E staining images of untreated and treated with $\mathrm{CP}, \mathrm{CPA}_{0.5}$, and $\mathrm{CPA}_{1}$.

have good biocompatibility and safety to be used for wound applications.

\section{Competing Interests}

The authors declare that they have no competing interests.

\section{Acknowledgments}

This work was supported by the fund of Vietnam National University, Ho Chi Minh City, under Grant no. B2013-76-03 and Grant no. 1161/QĐ-ĐHQG-KHCN.

\section{References}

[1] R. A. Franco, T. H. Nguyen, and B.-T. Lee, "Preparation and characterization of electrospun PCL/PLGA membranes and chitosan/gelatin hydrogels for skin bioengineering applications," Journal of Materials Science: Materials in Medicine, vol. 22, no. 10, pp. 2207-2218, 2011.

[2] K. T. Nguyen and J. L. West, "Photopolymerizable hydrogels for tissue engineering applications," Biomaterials, vol. 23, no. 22, pp. 4307-4314, 2002.
[3] C. Chen, L. Liu, T. Huang, Q. Wang, and Y. Fang, "Bubble template fabrication of chitosan/poly(vinyl alcohol) sponges for wound dressing applications," International Journal of Biological Macromolecules, vol. 62, pp. 188-193, 2013.

[4] H. Yu, X. Xu, X. Chen, T. Lu, P. Zhang, and X. Jing, "Preparation and antibacterial effects of PVA-PVP hydrogels containing silver nanoparticles," Journal of Applied Polymer Science, vol. 103, no. 1, pp. 125-133, 2007.

[5] Y. Zhou, Y. Zhao, L. Wang, L. Xu, M. Zhai, and S. Wei, "Radiation synthesis and characterization of nanosilver/gelatin/carboxymethyl chitosan hydrogel," Radiation Physics and Chemistry, vol. 81, no. 5, pp. 553-560, 2012.

[6] X. Zan, M. Kozlov, T. J. McCarthy, and Z. Su, "Covalently attached, silver-doped poly(vinyl alcohol) hydrogel films on poly(l-lactic acid)," Biomacromolecules, vol. 11, no. 4, pp. 10821088, 2010.

[7] C. Shi, Y. Zhu, X. Ran, M. Wang, Y. Su, and T. Cheng, “Therapeutic potential of chitosan and its derivatives in regenerative medicine," Journal of Surgical Research, vol. 133, no. 2, pp. 185192, 2006.

[8] M. Kong, X. G. Chen, K. Xing, and H. J. Park, "Antimicrobial properties of chitosan and mode of action: a state of the art review," International Journal of Food Microbiology, vol. 144, no. 1, pp. 51-63, 2010. 
[9] S. Agnihotri, S. Mukherji, and S. Mukherji, "Antimicrobial chitosan-PVA hydrogel as a nanoreactor and immobilizing matrix for silver nanoparticles," Applied Nanoscience, vol. 2, no. 3, pp. 179-188, 2012.

[10] L. Van der Schueren, I. Steyaert, B. De Schoenmaker, and K. De Clerck, "Polycaprolactone/chitosan blend nanofibres electrospun from an acetic acid/formic acid solvent system," Carbohydrate Polymers, vol. 88, no. 4, pp. 1221-1226, 2012.

[11] P. L. Nadworny, J. Wang, E. E. Tredget, and R. E. Burrell, "Antiinflammatory activity of nanocrystalline silver in a porcine contact dermatitis model," Nanomedicine: Nanotechnology, Biology, and Medicine, vol. 4, no. 3, pp. 241-251, 2008.

[12] J. Tian, K. K. Y. Wong, C.-M. Ho et al., "Topical delivery of silver nanoparticles promotes wound healing," ChemMedChem, vol. 2, no. 1, pp. 129-136, 2007.

[13] A. R. Shahverdi, A. Fakhimi, H. R. Shahverdi, and S. Minaian, "Synthesis and effect of silver nanoparticles on the antibacterial activity of different antibiotics against Staphylococcus aureus and Escherichia coli," Nanomedicine: Nanotechnology, Biology, and Medicine, vol. 3, no. 2, pp. 168-171, 2007.

[14] A. M. Fayaz, K. Balaji, M. Girilal, R. Yadav, P. T. Kalaichelvan, and R. Venketesan, "Biogenic synthesis of silver nanoparticles and their synergistic effect with antibiotics: a study against gram-positive and gram-negative bacteria," Nanomedicine: Nanotechnology, Biology, and Medicine, vol. 6, no. 1, pp. e103e109, 2010.

[15] J. F. Hernández-Sierra, F. Ruiz, D. C. Cruz Pena et al., "The antimicrobial sensitivity of Streptococcus mutans to nanoparticles of silver, zinc oxide, and gold," Nanomedicine: Nanotechnology, Biology, and Medicine, vol. 4, no. 3, pp. 237-240, 2008.

[16] J. S. Kim, E. Kuk, K. N. Yu et al., "Antimicrobial effects of silver nanoparticles," Nanomedicine: Nanotechnology, Biology, and Medicine, vol. 3, no. 1, pp. 95-101, 2007.

[17] M. Gajbhiye, J. Kesharwani, A. Ingle, A. Gade, and M. Rai, "Fungus-mediated synthesis of silver nanoparticles and their activity against pathogenic fungi in combination with fluconazole," Nanomedicine: Nanotechnology, Biology, and Medicine, vol. 5, no. 4, pp. 382-386, 2009.

[18] S. Kokura, O. Handa, T. Takagi, T. Ishikawa, Y. Naito, and T. Yoshikawa, "Silver nanoparticles as a safe preservative for use in cosmetics," Nanomedicine: Nanotechnology, Biology, and Medicine, vol. 6, no. 4, pp. 570-574, 2010.

[19] O. Choi, K. K. Deng, N.-J. Kim, L. Ross Jr., R. Y. Surampalli, and $\mathrm{Z}$. Hu, "The inhibitory effects of silver nanoparticles, silver ions, and silver chloride colloids on microbial growth," Water Research, vol. 42, no. 12, pp. 3066-3074, 2008.

[20] M. Sládková, B. Vlčková, I. Pavel, K. Šišková, and M. Šlouf, "Surface-enhanced Raman scattering from a single molecularly bridged silver nanoparticle aggregate," Journal of Molecular Structure, vol. 924-926, pp. 567-570, 2009.

[21] R. Foldbjerg, P. Olesen, M. Hougaard, D. A. Dang, H. J. Hoffmann, and H. Autrup, "PVP-coated silver nanoparticles and silver ions induce reactive oxygen species, apoptosis and necrosis in THP-1 monocytes," Toxicology Letters, vol. 190, no. 2, pp. 156-162, 2009.

[22] S. K. Mishra, J. M. F. Ferreira, and S. Kannan, "Mechanically stable antimicrobial chitosan-PVA-silver nanocomposite coatings deposited on titanium implants," Carbohydrate Polymers, vol. 121, pp. 37-48, 2015.

[23] O. Lyutakov, I. Goncharova, S. Rimpelova, K. Kolarova, J. Svanda, and V. Svorcik, "Silver release and antimicrobial properties of PMMA films doped with silver ions, nano-particles and complexes," Materials Science and Engineering: C, vol. 49, pp. 534-540, 2015.

[24] R. C. Goy, D. de Britto, and O. B. G. Assis, "A review of the antimicrobial activity of chitosan," Polimeros, vol. 19, no. 3, pp. 241-247, 2009.

[25] W. K. Jung, H. C. Koo, K. W. Kim, S. Shin, S. H. Kim, and Y. H. Park, "Antibacterial activity and mechanism of action of the silver ion in Staphylococcus aureus and Escherichia coli," Applied and Environmental Microbiology, vol. 74, no. 7, pp. 2171-2178, 2008.

[26] C. Sámano-Valencia, G. A. Martínez-Castañón, F. MartínezGutiérrez et al., "Characterization and biocompatibility of chitosan gels with silver and gold nanoparticles," Journal of Nanomaterials, vol. 2014, Article ID 543419, 11 pages, 2014.

[27] S. Akmaz, E. D. Adıgüzel, M. Yasar, and O. Erguven, "The effect of Ag content of the chitosan-silver nanoparticle composite material on the structure and antibacterial activity," Advances in Materials Science and Engineering, vol. 2013, Article ID 690918, 6 pages, 2013.

[28] M. B. Ahmad, M. Y. Tay, K. Shameli, M. Z. Hussein, and J. J. Lim, "Green synthesis and characterization of silver/chitosan/polyethylene glycol nanocomposites without any reducing agent," International Journal of Molecular Sciences, vol. 12, no. 8, pp. 4872-4884, 2011.

[29] T.-H. Nguyen, K.-H. Lee, and B.-T. Lee, "Fabrication of Ag nanoparticles dispersed in PVA nanowire mats by microwave irradiation and electro-spinning," Materials Science and Engineering C, vol. 30, no. 7, pp. 944-950, 2010.

[30] T.-H. Nguyen, Y.-H. Kim, H.-Y. Song, and B.-T. Lee, "Nano Ag loaded PVA nano-fibrous mats for skin applications," Journal of Biomedical Materials Research Part B: Applied Biomaterials, vol. 96, no. 2, pp. 225-233, 2011.

[31] J. Krstić, J. Spasojević, A. Radosavljević et al., "In vitro silver ion release kinetics from nanosilver/poly(vinyl alcohol) hydrogels synthesized by gamma irradiation," Journal of Applied Polymer Science, vol. 131, no. 11, Article ID 40321, 2014.

[32] X. Wu, J. Li, L. Wang, D. Huang, Y. Zuo, and Y. Li, “The release properties of silver ions from $\mathrm{Ag}-\mathrm{nHA} / \mathrm{TiO}_{2} / \mathrm{PA} 66$ antimicrobial composite scaffolds," Biomedical Materials, vol. 5, no. 4, Article ID 044105, 2010.

[33] A. F. Visentin, T. Dong, J. Poli, and M. J. Panzer, "Rapid, microwave-assisted thermal polymerization of poly(ethylene glycol) diacrylate-supported ionogels," Journal of Materials Chemistry A, vol. 2, no. 21, pp. 7723-7726, 2014.

[34] C. W. Li, R. Q. Fu, C. P. Yu et al., "Silver nanoparticle/chitosan oligosaccharide/poly(vinyl alcohol) nanofibers as wound dressings: a preclinical study," International Journal of Nanomedicine, vol. 8, pp. 4131-4145, 2013.

[35] J. Krstić, J. Spasojević, A. Radosavljević, M. Šiljegovć, and Z. Kačarević-Popović, "Optical and structural properties of radiolytically in situ synthesized silver nanoparticles stabilized by chitosan/poly(vinyl alcohol) blends," Radiation Physics and Chemistry, vol. 96, pp. 158-166, 2014.

[36] P. B. Palani, K. S. Abidin, R. Kannan et al., "Improvement of proton conductivity in nanocomposite polyvinyl alcohol (PVA)/chitosan (CS) blend membranes," RSC Advances, vol. 4, no. 106, pp. 61781-61789, 2014.

[37] S. N. Alhosseini, F. Moztarzadeh, M. Mozafari et al., "Synthesis and characterization of electrospun polyvinyl alcohol nanofibrous scaffolds modified by blending with chitosan for neural tissue engineering," International Journal of Nanomedicine, vol. 7, pp. 25-34, 2012. 
[38] Y. Murali Mohan, K. Lee, T. Premkumar, and K. E. Geckeler, "Hydrogel networks as nanoreactors: a novel approach to silver nanoparticles for antibacterial applications," Polymer, vol. 48, no. 1, pp. 158-164, 2007.

[39] I. Tarnavchyk, A. Voronov, A. Kohut et al., "Reactive hydrogel networks for the fabrication of metal-polymer nanocomposites," Macromolecular Rapid Communications, vol. 30, no. 18, pp. 1564-1569, 2009.

[40] D. K. Boanić, L. V. Trandafilović, A. S. Luyt, and V. Djoković, "'Green' synthesis and optical properties of silver-chitosan complexes and nanocomposites," Reactive and Functional Polymers, vol. 70, no. 11, pp. 869-873, 2010.

[41] M. N. Nadagouda and R. S. Varma, "Microwave-assisted synthesis of crosslinked poly(vinyl alcohol) nanocomposites comprising single-walled carbon nanotubes, multi-walled carbon nanotubes, and buckminsterfullerene," Macromolecular Rapid Communications, vol. 28, no. 7, pp. 842-847, 2007.

[42] C. Beer, R. Foldbjerg, Y. Hayashi, D. S. Sutherland, and H. Autrup, "Toxicity of silver nanoparticles-nanoparticle or silver ion?” Toxicology Letters, vol. 208, no. 3, pp. 286-292, 2012. 

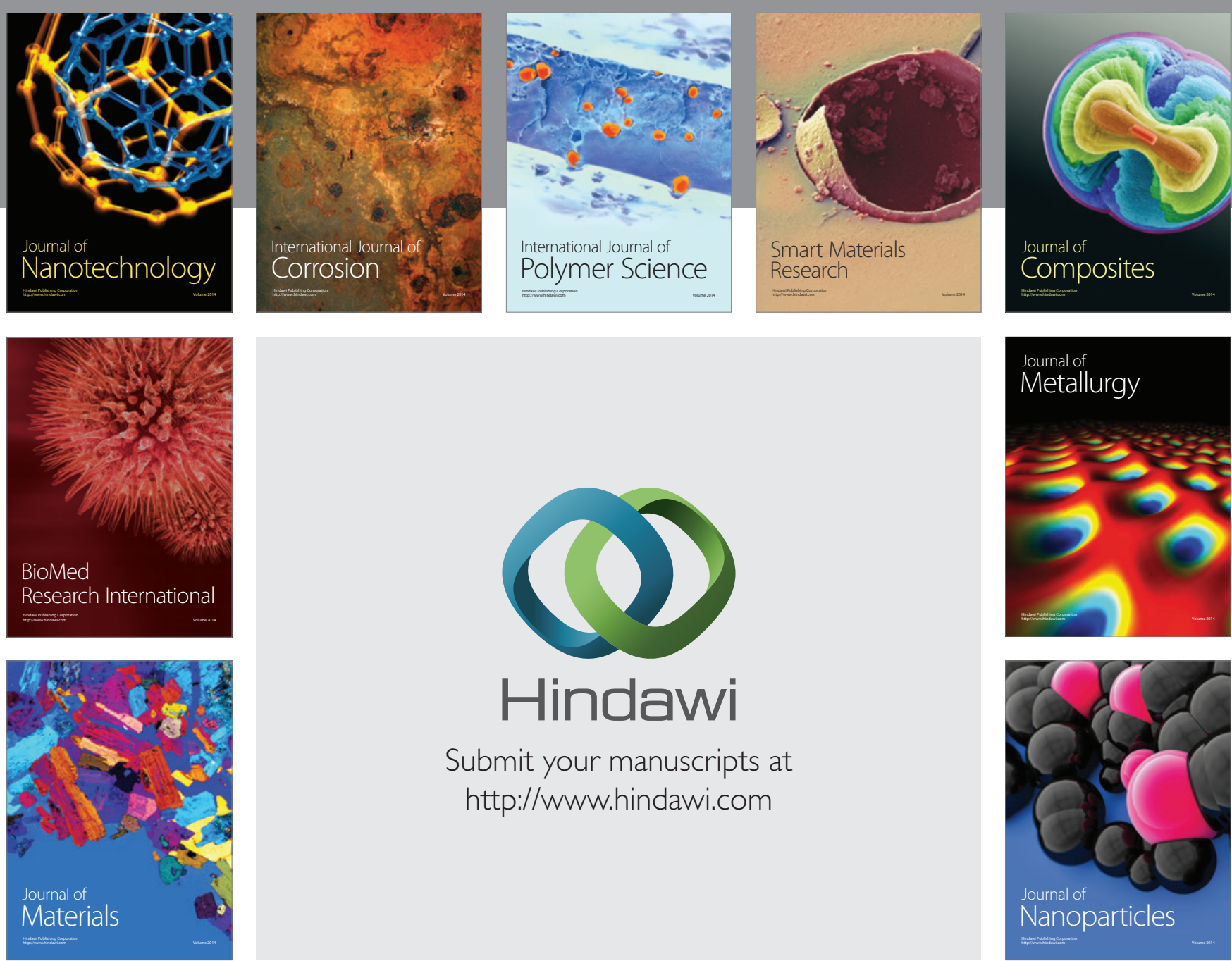

\section{Hindawi}

Submit your manuscripts at

http://www.hindawi.com

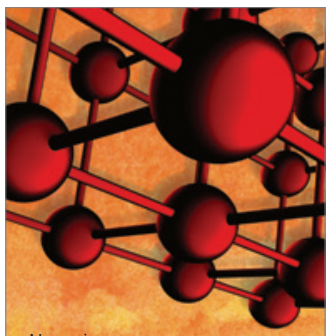

Materials Science and Engineering
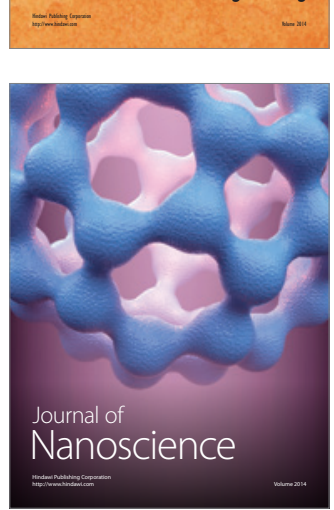
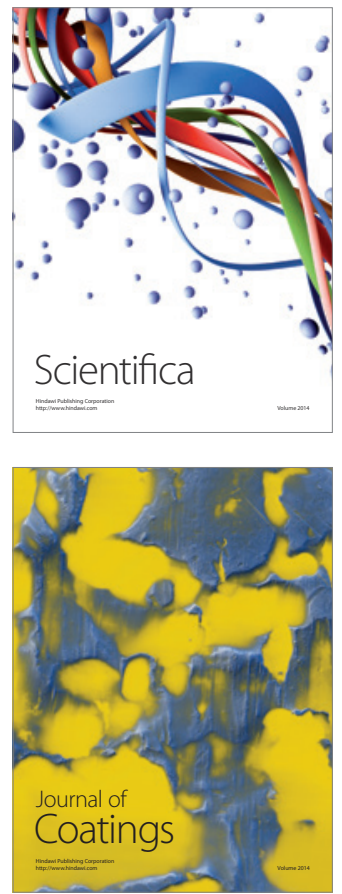
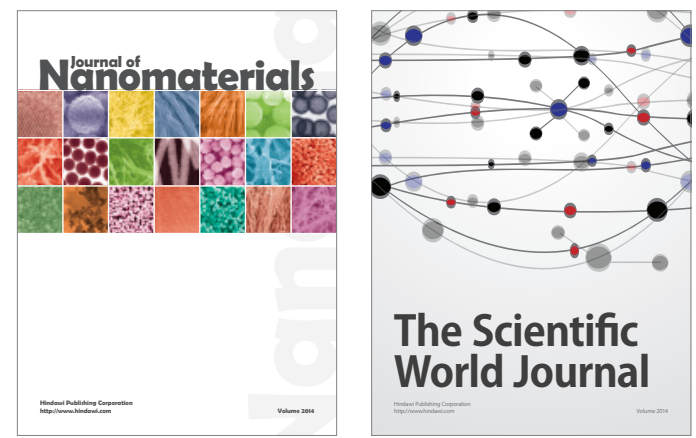

The Scientific World Journal
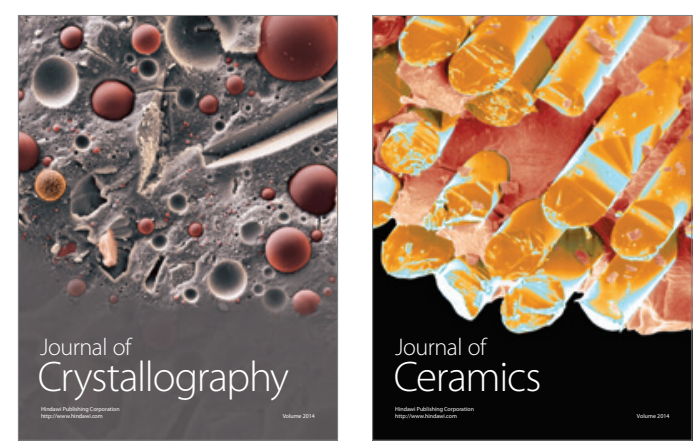
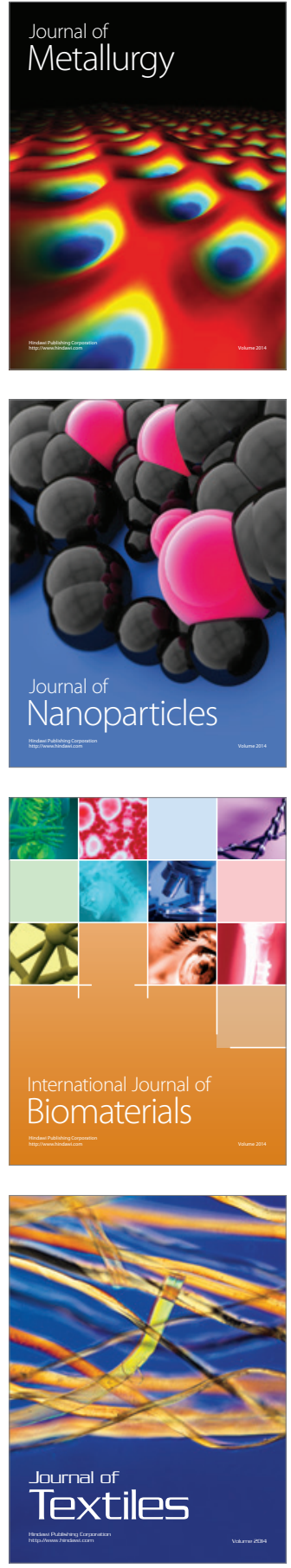